\title{
Gestão por indicadores de desempenho: resultados na incubadora empresarial tecnológica
}

\author{
Mauro Pacheco Ferreira UNISUL \\ Aline França de Abreu UFSC \\ Pedro Felipe de Abreu UFSC \\ Dorzeli Salete Trzeciak UFSC \\ Luiz Gonzaga Apolinário Incubadora MIDI-Tecnológico \\ Alexandre d'Avila da Cunha ACATE
}

\section{RESUMO}

Em função da relevância de mecanismos fortes de suporte à gestão empresarial nas incubadoras, para que possam auxiliar de forma eficiente no processo de negócio das novas empresas e, conseqüentemente, aumentar suas chances de sucesso, este artigo visa apresentar uma proposta de gestão por indicadores de desempenho para empresas de base tecnológica em formação e crescimento. Logo, compreende a conceituação necessária à concepção do modelo, o estabelecimento de uma empresa padrão no contexto de incubação, a definição das bases de direcionamento para o estabelecimento de indicadores de desempenho e a formatação de uma planilha de indicadores de desempenho e coleta de dados para avaliação. De forma conclusiva, apresenta considerações positivas sobre o modelo desenvolvido na prática.

\section{PALAVRAS-CHAVE}

Gestão de negócios. Incubadora empresarial. Indicadores de desempenho.

\section{Management through performance indicators: results in a technological business incubator}

\begin{abstract}
Based in the relevance of strong support mechanisms for business management, that can help in an efficient manner in the business process of new enterprises and as a consequence increases their chances of success, this paper aims to present a proposal of management through performance indicators to technological based enterprises in development and growth. It consists on the theoretical grounding needed for the conception of a model, the estabilishment of a standard enterprise in the context of incubation, the definition of the directing bases for the establishment of performance indicators and the formatting of a performance indicator spreadsheet and collecting data for evaluation. In a conclusive way, it presents positive consideration about the developed model in practical application.
\end{abstract}

\section{KEY WORDS}

Business management, business incubator, performance indicator. 


\section{INTRODUÇÃO}

A alta taxa de mortalidade das novas micro e pequenas empresas indica a necessidade de suporte acentuado na gestão das empresas em busca do alcance de seus objetivos de negócio. Alguns indicadores estabelecem que mais de 50\% destas empresas estão fechando no primeiro ano de existência e mais de 60\%, no segundo ano (SEBRAE-SC, 2001). Para as empresas de base tecnológica a taxa de mortalidade chega a $90 \%$.

Também observa-se no mercado financeiro uma timidez dos investidores para os novos negócios, que é representada por altas taxas de juros, exigências de garantias e um baixo índice de aplicações de capital de risco. Estas atitudes são reflexos do alto risco associados, aos novos empreendimentos.

Para amenizar este panorama, desde 1985, as Incubadoras Empresariais vêm sendo utilizadas no Brasil para estimular a criação, o desenvolvimento e a consolidação de micro e pequenas empresas (MEDEIROS et al., 1992; ANPROTEC, 2001). Provêem a aceleração do processo de criação e o aumento das chances de sobrevivência das novas empresas. Através do processo de incubação em suas estruturas, abrigam e suportam as novas empresas, propiciando uma série de serviços e facilidades.

De maneira deficiente, muitas incubadoras, atualmente, ainda não dispõem de mecanismos fortes de suporte à gestão empresarial, ficando muitas vezes limitadas ao fornecimento de estrutura física e serviços de apoio, não podendo auxiliar de forma benéfica no processo de negócio da nova empresa.

Para a redução dos riscos durante o processo de formação das novas empresas, é sensível a necessidade de implantação de mecanismos de gestão empresarial capazes de dar visibilidade à evolução do negócio, apoiando o fortalecimento da produtividade e o aumento da competitividade no mercado (FERREIRA, 2002).

Neste sentido, apresenta-se a execução de uma proposta que implicou na aplicação prática de técnicas de gestão adaptadas à realidade de empresas incubadas em fase de formação e crescimento (FERREIRA et al., 2001). Envolveu a estrutura de uma incubadora de empresas de base tecnológica, ainda jovem em seus processos de negócio, resultando num amplo conjunto de experiências e aprendizados, que por si só, acredita-se ter fortalecido o processo de formação de novas empresas. A execução desta proposta é apresentada sob o enfoque principal da gestão por indicadores de desempenho.

\section{JUSTIFICATIVA PARA INDICADORES DE DESEMPENHO}

Para sobreviver ao ambiente de negócios turbulento e dinâmico e à competição global do mercado, as empresas devem ter reações cada vez mais rápidas, sempre direcionando suas ações de forma a manter-se firmes aos seus objetivos estratégicos (MCGEE; PRUSAK, 1994). Os indicadores de desempenho são elaborados no sentido de auxiliar os "tomadores de decisão" a avaliar a performance de uma unidade de negócio e redirecionar seus investimentos, de forma rápida e eficaz (CAULLIRAUX et al., 2001; FISCHMANN; ZILBER, 2001).

Um sistema de indicadores afeta, fortemente, o comportamento das pessoas dentro e fora da empresa. Se quiserem prosperar na era da informação, as empresas devem utilizar sistemas de gestão e medição de desempenho derivados de suas estratégias e capacidades. Os indicadores são utilizados para informar a empresa sobre os vetores de sucesso atual e futuro. Ao articularem os resultados desejados com os vetores desses resultados, os administradores esperam canalizar as energias, habilidades e conhecimentos específicos das pessoas na empresa inteira para alcançar as metas de longo prazo (KAPLAN; NORTON, 1997).

\section{s indicadores são utilizados para informar a empresa sobre os vetores de sucesso atual e futuro.}

Um sistema de gestão baseado em indicadores estabelece um mecanismo que gera visibilidade do desempenho das empresas e de suas características de qualidade, tornando o ambiente de negócios mais seguro e controlado, de modo a atrair um número maior de investidores.

A avaliação do desempenho empresarial baseada apenas em indicadores contábeis e financeiros tem se mostrado insuficiente para as organizações. A ênfase excessiva em resultados financeiros de curto prazo pode levar a soluções rápidas, porém superficiais. De acordo com Caulliraux et al. (2001) a própria Fundação para o Prêmio Nacional da Qualidade define desempenho como os resultados que se obtêm de processos e de produtos, permitindo avaliá-los e compará-los em relação às metas, aos padrões, aos resultados históricos e a outros processos e produtos.

Dessa forma, visando aumentar as chances de sucesso das novas empresas, o principal objetivo desta proposta foi introduzir, no processo de incubação de empresas, um sistema de gestão empresarial baseado em indicadores de desempenho, que abrangesse tanto o processo de incubação 
oferecido na incubadora, quanto a estrutura das empresas incubadas. Além disso, busca possibilitar a monitoração da execução do plano de negócios, bem como a realimentação da empresa para a atuação no mercado.

\section{ABORDAGEM DO BALANCED SCORECARD}

Um sistema de medidas de desempenho que alcançou destaque em função da obsolescência dos tradicionais indicadores de desempenho foi o Balanced Scorecard - cartão equilibrado de marcação de pontos (SILVA NETO, 2000), apresentado pelos americanos Robert Kaplan e David Norton, professores da Harvard Business School (HERZOG, 2001).
O Balanced Scorecard é uma ferramenta que traduz a missão e a estratégia das empresas num conjunto abrangente e consistente de medidas de desempenho que serve de base para um sistema de medição e gestão estratégica. Conforme Kaplan e Norton (1997) a filosofia do Balanced Scorecard é adotada para:

- esclarecer e traduzir a visão e a estratégia;

- comunicar e associar objetivos e medidas estratégicas;

- planejar, estabelecer metas e alinhar iniciativas estratégicas;

- melhorar o feedback e o aprendizado estratégico.

O termo balanced - equilibrado - refere-se ao fato de que a abordagem é sustentada através de um conjunto harmônico de medidas que contrabalança forças de natureza externa e forças de natureza interna da organização (SILVA NETO, 2000).

Kaplan e Norton (1997) contemplam quatro perspectivas na abordagem do Balanced Scorecard:

a) perspectiva financeira: os objeti-

A esta proposta de Kaplan e Norton (1997) associa-se o seguinte histórico:

- observando que os métodos apoiados nos indicadores contábeis e financeiros estavam obsoletos e que geravam prejuízo na capacidade da empresa em criar valor econômico para o futuro, foi identificada a necessidade de criação de sistema equilibrado de medição para atender a objetivos de curto e longo prazo das organizações, com medidas financeiras e não financeiras, indicadores de tendência e ocorrências, além de uma perspectiva interna e externa de desempenho. O artigo "Measuring Performance in the Organization of the Future", publicado em 1990, retrata esta visão;

- com a visão de que indicadores para comunicar novas estratégias e alinhar as empresas a elas facilitariam a tradução e implementação de estratégias, uma ampliação das perspectivas dos indicadores foi proposta no artigo "The Balances Scorecard - Measures that Drive Performance", publicado em 1992;

- a importância da escolha de medidas (indicadores) baseadas no sucesso estratégico foi fortalecida no artigo: "Putting the Balanced Scorecard to Work", publicado em 1993;

- o gerenciamento da estratégia através da utilização de indicadores em importantes processos gerenciais foi o enfoque do artigo "Using the Balanced Scorecard as a Strategic Management System", publicado em 1996, no qual foi consolidada a proposta de indicadores. vos financeiros servem de foco para os objetivos e medidas das outras perspectivas. Qualquer medida relacionada deve fazer parte de uma cadeia de relações de causa e efeito, que culminam com a melhoria do desempenho financeiro. $\mathrm{O}$ estágio de maturidade da empresa, em seu ciclo de vida, resulta em diferenças consideráveis nos objetivos financeiros das organizações;

b) perspectiva dos clientes: a perspectiva dos clientes deve, a princípio, identificar os segmentos e mercados alvos nos quais a empresa pretende competir, além de traduzir a missão e a estratégia da empresa em objetivos específicos para estes segmentos focalizados, podendo ser comunicados a toda organização. O segredo para o desenvolvimento de objetivos e medidas na perspectiva dos clientes está na identificação de propostas de valor dirigidas aos segmentos escolhidos para atuação;

c) perspectiva dos processos internos da empresa: nesta perspectiva, são enfocados os processos mais críticos para a satisfação das expectativas dos clientes e acionistas. É recomendada a definição de uma cadeia de valor completa dos processos internos, com início no processo de inovação, passando pelo processo de operações e finalizando nos serviços da pós-venda;

d) perspectiva do aprendizado e crescimento: a perspectiva do aprendizado e crescimento no Balanced Scorecard objetiva oferecer a infra-estrutura que possibilita o alcance dos objetivos das outras três perspectivas. Tem como tema central o estado dos recursos humanos com o capital inte- 
lectual e os meios que a organização oferece para a plena atuação de seus colaboradores.

Os indicadores não são apenas um conjunto de fatores críticos ou fatores-chave de sucesso. Kaplan e Norton (1997, p. 30) explicam que "as diversas medidas devem compor uma série articulada de objetivos e medidas coerentes que se reforcem mutuamente". A idéia é que o Balanced Scorecard deve se comportar como um mecanismo de simulação da empresa e não apenas como um sinalizador. Deve conter um conjunto complexo de relações de causa e efeito (hipóteses) entre variáveis críticas que permeiam todas as quatro perspectivas propostas. Envolve indicadores de fatos (medidas) e de tendências (vetores de desempenho) que descrevem a trajetória da estratégia definida, para realimentação através de ciclos de feedback.

A montagem do Balanced Scorecard parte da tradução da estratégia da empresa em objetivos estratégicos específicos, estabelecendo metas para a perspectiva financeira e para a perspectiva dos clientes. Aqui deve ser priorizada a receita, o crescimento de mercado, a lucratividade e a geração de fluxo de caixa, bem como a clareza quanto a segmentos de clientes e mercados de atuação. Posteriormente, devem-se identificar os objetivos e medidas para os processos internos da organização, buscando o enfoque de questões relacionadas ao alcance de um desempenho superior para clientes e acionistas. Finalmente, a perspectiva do aprendizado e crescimento deve ser estabelecida à produção de melhorias e inovações para os processos internos de negócios. Reflete os investimentos que elevam os resultados futuros (KAPLAN; NORTON, 1997; SILVA NETO, 2000).

Um requisito para a formação do sistema de medição do Balanced Scorecard é a utilização de um número restrito de medidas em cada uma das perspectivas, exigindo um maior foco na visão estratégica. Para cada perspectiva são elaborados dois conjuntos de indicadores: as medidas de resultados e os vetores de desempenho. As medidas de resultado, também referidas como estado, ocorrência, essenciais ou genéricas, tem por finalidade avaliar e acompanhar o estado atual, os resultados apresentados. A identificação das medidas de resultado é originada do questionamento sobre como a empresa alcançou seus objetivos estratégicos na referida perspectiva. Os vetores de desempenho, medidas de tendência ou medidas estratégicas, têm por finalidade descrever e acompanhar aqueles vetores considerados responsáveis pela performance futura de cada perspectiva (SILVA NETO, 2000).

\section{BALANCED SCORECARD APLICADO AO CONTEXTO DA INCUBAÇÃO DE EMPRESAS DE BASE TECNOLÓGICA}

Com diferenciação peculiar de outras empresas, as empresas de alta tecnologia são caracterizadas, conforme a visão de Riggs (1983), como sendo empresas onde a tecnologia é considerada um elemento chave na estratégia empresarial. $\mathrm{Na}$ abordagem das fases menos avançadas da tecnologia e de mercado, quando a incerteza com relação à tecnologia e sistemas de produção é bastante grande, as empresas são denominadas Empresas de Base Tecnológica (EBTs) (SEBRAE-SP, 2001). Utilizam os conhecimentos científicos e tecnológicos como seu maior insumo de produção para a geração de produtos ou serviços inovadores (SANTOS apud BASTO, 2000; MEDEIROS et al., 1992).

Neste contexto, não se conhece bem a trajetória tecnológica de resolução de problemas, existem dúvidas sobre o funcionamento dos novos produtos, sobre a obsoletização das tecnologias vigentes, efeitos imprevistos da tecnologia, prazos de colocação do produto no mercado e garantia de qualidade do serviço. Outras incertezas são relativas à tecnologia com o mercado, à velocidade de sua disseminação, ao padrão adotado pelos clientes e às futuras mudanças nas necessidades desses clientes (SEBRAE-SP, 2001).

\section{Empresas de Base Tecnológica utilizam conhecimentos — científicos e tecnológicos como insumo de produção para gerar produtos ou serviços inovadores.}

De acordo com diversos autores, não existe uma definição única para o conceito de empresas de base tecnológica (SEBRAE-SP, 2001).

Riggs (1983) destaca algumas características das empresas de tecnologia:

- são populadas por engenheiros e técnicos, que consomem boa parte dos recursos da empresa e que também estão presentes nas áreas de vendas e marketing;

- o ciclo de vida dos produtos é cada vez mais curto;

- apresentam mudanças freqüentes em produtos, tecnologias e na posição competitiva no mercado;

- o cenário de atuação apresenta presença permanente de riscos.

Considera-se importante destacar o contexto das empresas de base tecnológica em fase de formação e crescimento, alvo desta proposta de sistema de gestão empresarial baseado 
em indicadores de desempenho. O somatório dos riscos permanentes e das mudanças rápidas necessárias gera um forte panorama de instabilidade para este tipo de empresa.

De posse dos conceitos do Balanced Scorecard e considerando o contexto das empresas de base tecnológica em formação e crescimento, na seqüência, é apresentado o desenvolvimento prático do modelo proposto.

\subsection{Identificação do processo de empresa padrão}

Uma questão fundamental para a definição de indicadores de desempenho nas empresas incubadas foi estabelecer uma descrição referência de processos para as empresas. Apesar da identificação de processos das empresas ter sido desenvolvida de forma individual, uma estrutura padrão de processos foi estabelecida através do levantamento das melhores práticas encontradas nas empresas incubadas, pois o tratamento de particularidades de cada empresa incubada geraria uma alta complexidade no mecanismo de gestão.

Um organograma (Figura 1) e um funcionograma (Tabela 1) foram definidos com a abordagem de um modelo de responsabilidades e são apresentados a seguir.

Em todas as empresas foram identificadas atividades para a oferta no mercado de hardware, software, integração de hardware e software, e serviços, sempre envolvendo a implementação de novas tecnologias.

O macro-processo da empresa referência (Figura 2) reflete a linha de negócios principal da empresa de base tecnológica incubada. Abrange o caminho desde a formação do produto até seu estabelecimento no mercado, englobando também o suporte empresarial necessário.

Os processos empresariais podem ser relacionados com a execução de atividades associadas ao organograma e funcionograma da empresa. A Tabela 2 apresenta esta associação.

\subsection{Desenvolvimento do modelo de gestão por indicadores de desempenho}

Os indicadores de desempenho foram estabelecidos como um instrumento gerencial para evidenciar as tendências de sucesso ou fracasso das empresas incubadas. São uma ferramenta tanto para as empresas quanto para a estrutura administrativa da incubadora que acompanha o desenvolvimento das empresas.

A verificação destes indicadores foi sugerida para ser feita junto às atividades de planejamento nas empresas e junto ao sistema de avaliação da incubadora.

O conjunto inicial de indicadores foi estabelecido com base em pesquisas junto às empresas industriais e de serviços realizadas pela comunidade científica, na pesquisa sobre a mortalidade de empresas e seus fatores condicionantes realizada pelo SEBRAE-SC (1999) e na vivência do levantamento de processos na incubadora e em suas empresas incubadas.

O enfoque de definição dos indicadores esteve direcionado para a identificação da empresa graduada, ou seja, no estágio de desacoplamento do processo de incubação, capaz de dar continuidade ao seu plano de negócio de forma independente da estrutura de suporte da incubadora. A empresa graduada foi definida conforme a lista de características apresentadas a seguir:

- desenvolveu e implantou o plano de negócio;

- carteira de clientes que garanta a sustentabilidade da empresa;

- produtos e serviços definidos;

- visão de marketing implementada (imagem da empresa constituída);

- domínio tecnológico e competências claramente definidos;

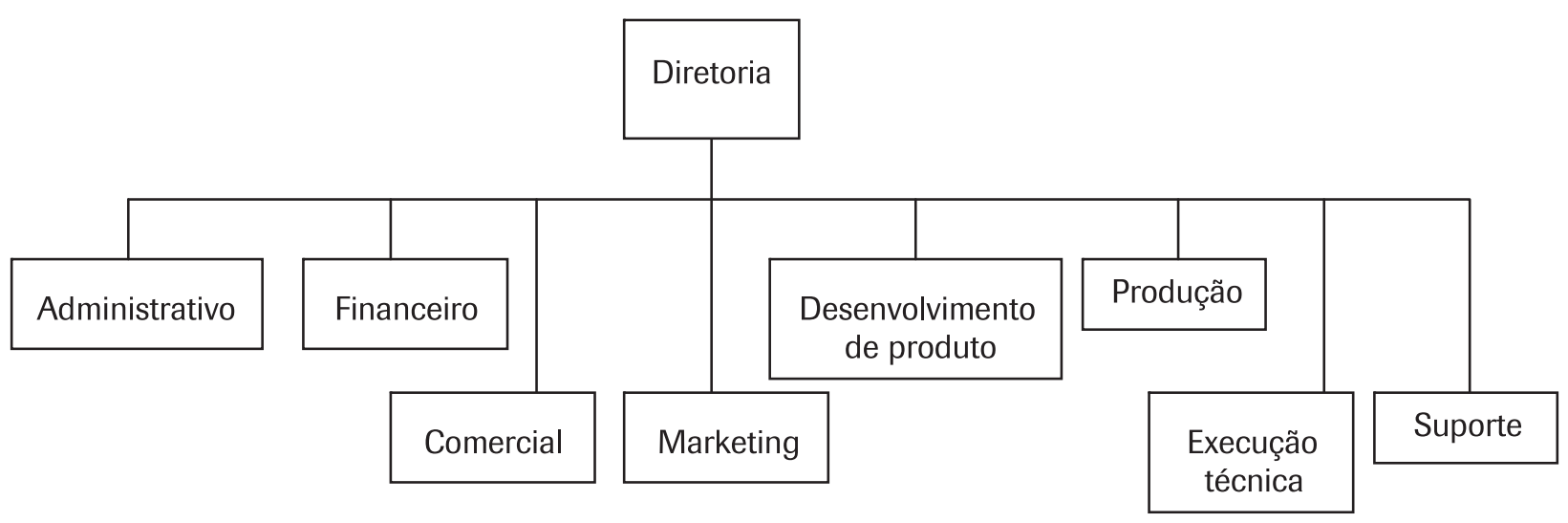

Figura 1. Organograma 
Tabela 1: Funcionograma.

\begin{tabular}{|c|c|}
\hline Segmento & Funções \\
\hline Diretoria & - Decisões estratégicas \\
\hline Administrativo & $\begin{array}{l}\text { - Controle de recursos humanos } \\
\text { - Planejamento estratégico } \\
\text { - Suporte jurídico } \\
\text { - Comunicação e integração da empresa }\end{array}$ \\
\hline Financeiro & $\begin{array}{l}\text { - Relacionamento com a contabilidade } \\
\text { - Controle de contas a pagar e a receber } \\
\text { - Controle do fluxo de caixa } \\
\text { - Simulação empresarial (projeção de resultados e cenários) }\end{array}$ \\
\hline Comercial & $\begin{array}{l}\text { - Elaboração de propostas } \\
\text { - Manutenção da carteira de clientes } \\
\text { - Elaboração de contratos } \\
\text { - Acompanhamento pós-vendas } \\
\text { - Estabelecimento de parcerias } \\
\text { - Identificação de necessidades do mercado }\end{array}$ \\
\hline Marketing & $\begin{array}{l}\text { - Imagem da empresa } \\
\text { - Manutenção da rede de relacionamento } \\
\text { - Logística de distribuição }\end{array}$ \\
\hline Desenvolvimento de produto & $\begin{array}{l}\text { - Projeto de hardware (mecânico e eletrônico) } \\
\text { - Projeto de software } \\
\text { - Prototipação } \\
\text { - Integração de hardware e software } \\
\text { - Empacotamento do produto } \\
\text { - Coordenação de projetos }\end{array}$ \\
\hline Produção & $\begin{array}{l}\text { - Compras } \\
\text { - Estoque } \\
\text { - Fabricação } \\
\text { - Testes } \\
\text { - Embalagem } \\
\text { - Entrega (envio/despacho) }\end{array}$ \\
\hline Execução técnica & $\begin{array}{l}\text { - Implantação de tecnologia } \\
\text { - Treinamento para usos do produto }\end{array}$ \\
\hline Suporte & $\begin{array}{l}\text { - Atendimento ao cliente } \\
\text { - Assistência técnica }\end{array}$ \\
\hline
\end{tabular}

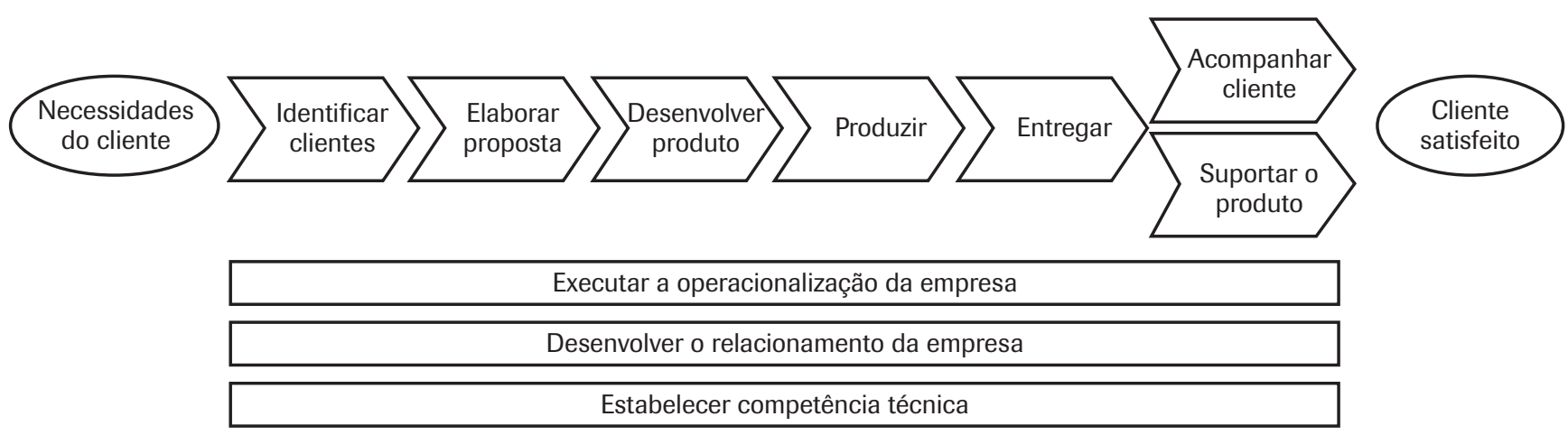

Figura 2: Macro-processo. 
- modelo de gestão constituído e compartilhado com os membros da empresa (áreas de responsabilidade - funções e processos);
- desempenho financeiro;

- capital social formado (rede de relacionamento);

- habilidades empreendedoras (perfil do empreendedor).

Quadro 2: Processos x organograma e funcionograma.

\begin{tabular}{|c|c|c|}
\hline Processo & & Atividades \\
\hline \multirow[t]{2}{*}{ Identificar clientes } & Diretoria & - Decisões estratégicas \\
\hline & Comercial & $\begin{array}{l}\text { - Manutenção da carteira de clientes } \\
\text { - Identificação de necessidades do mercado }\end{array}$ \\
\hline \multirow[t]{2}{*}{ Elaborar proposta } & Comercial & $\begin{array}{l}\text { - Elaboração de propostas } \\
\text { - Elaboração de contratos }\end{array}$ \\
\hline & Desenvolvimento de produto & - Prototipação \\
\hline \multirow{2}{*}{$\begin{array}{l}\text { Desenvolver } \\
\text { produto }\end{array}$} & Comercial & - Identificação de necessidades do mercado \\
\hline & Desenvolvimento de produto & $\begin{array}{l}\text { - Projeto de hardware (mecânico e eletrônico) } \\
\text { - Projeto de software } \\
\text { - Prototipação } \\
\text { - Integração de hardware e software }\end{array}$ \\
\hline \multirow[t]{2}{*}{ Produzir } & Desenvolvimento de produto & - Empacotamento do produto \\
\hline & Produção & $\begin{array}{l}\text { - } \text { Compras } \\
\text { - Estoque } \\
\text { - Fabricação } \\
\text { - Testes }\end{array}$ \\
\hline \multirow[t]{2}{*}{ Entregar } & Produção & $\begin{array}{l}\text { - Embalagem } \\
\text { - Entrega (envio/despacho) }\end{array}$ \\
\hline & Execução técnica & $\begin{array}{l}\text { - Implantação de tecnologia } \\
\text { - Treinamento para uso do produto }\end{array}$ \\
\hline Acompanhar cliente & Comercial & - Acompanhamento pós-vendas \\
\hline \multirow[t]{2}{*}{ Suportar produto } & Suporte & $\begin{array}{l}\text { - Atendimento ao cliente } \\
\text { - Assistência técnica }\end{array}$ \\
\hline & Execução técnica & - Treinamento para usos do produto \\
\hline \multirow[t]{3}{*}{$\begin{array}{l}\text { Executar } \\
\text { operacionalização } \\
\text { da empresa }\end{array}$} & Financeiro & $\begin{array}{l}\text { - Relacionamento com a contabilidade } \\
\text { - Controle de contas a pagar e a receber } \\
\text { - Controle do fluxo de caixa }\end{array}$ \\
\hline & Administrativo & $\begin{array}{l}\text { - Controle de recursos humanos } \\
\text { - Planejamento estratégico } \\
\text { - Suporte jurídico } \\
\text { - Comunicação e integração da empresa }\end{array}$ \\
\hline & Desenvolvimento de produto & - Coordenação de projetos \\
\hline \multirow{4}{*}{$\begin{array}{l}\text { Desenvolver } \\
\text { relacionamento } \\
\text { da empresa }\end{array}$} & Diretoria & - Decisões estratégicas \\
\hline & Financeiro & - Simulação empresarial (projeção de resultados e cenários) \\
\hline & Marketing & $\begin{array}{l}\text { - Imagem da empresa } \\
\text { - Manutenção da rede de relacionamento } \\
\text { - Logística de distribuição }\end{array}$ \\
\hline & Comercial & - Estabelecimento de parcerias \\
\hline \multirow{2}{*}{$\begin{array}{c}\text { Estabelecer } \\
\text { competência técnica }\end{array}$} & Diretoria & - Decisões estratégicas \\
\hline & Administrativo & $\begin{array}{l}\text { - Controle de recursos humanos } \\
\text { - Planejamento estratégico }\end{array}$ \\
\hline
\end{tabular}


A imaturidade de processos encontrada durante a etapa de levantamento conduziu a uma abordagem mais pragmática para a definição de indicadores de desempenho. Um conjunto inicial foi estabelecido para a posterior evolução conforme sua aplicabilidade. Os parâmetros tomados como referência para o estabelecimento de indicadores de desempenho foram baseados em fatores críticos de sucesso, áreas chaves de gestão e nos próprios processos da incubadora e das empresas incubadas.

\subsubsection{Indicadores de desempenho - fatores críticos de sucesso}

A pesquisa realizada pelo SEBRAE-SC (1999) apontou os seguintes fatores críticos de sucesso para as empresas (ordem decrescente):

- capacidade do empresário para assumir riscos;

- aproveitamento das oportunidades de negócio;

- ter um bom administrador;

- bom conhecimento do mercado onde atua;

- capacidade de liderança do empresário;

- uso de capital próprio;

- criatividade do empresário;

- reinvestimento dos lucros na empresa;

- boa estratégia de vendas;

- terceirização das atividades meio da empresa;

- ter acesso às novas tecnologias;

- empresário com persistência/perseverança;

- outros: ter dinheiro, ter um bom contador, bom atendimento, conhecimento do cliente, clientela, sorte, treinamento de pessoal, experiência, mão-de-obra qualificada, ser recebido no local.

Algumas dificuldades também são relacionadas pelo SEBRAE-SC (1999): falta de capital de giro, problemas com mão-de-obra, falta de clientes, concorrência forte, carga tributária elevada, maus pagadores, burocracia, recessão econômica, compras, falta de apoio das instituições, falta de crédito, problemas financeiros, desconhecimento do mercado, vendas, desentendimento entre os sócios, falta de investimentos, falta de informações sobre legislação, qualidade de serviços, marketing, problemas com fiscalização, instalações inadequadas, perfil socioeconômico da clientela, cobrança, falta de conhecimentos gerenciais, excesso de trabalho, margem baixa de lucro, aluguel, contador, representantes, falta de informação, entrega, mercado de atuação, falta de ética, participar de concorrências, centralização das informações, falta de união do setor, não ter sede própria, gerenciamento administrativo, penetração de produto novo no mercado, demora do retorno dos pagamentos, importação, ponto inadequado, produtos que não eram de primeira necessidade, discriminação, equipamentos, desconhecimento da tecnologia de produção.

\subsubsection{Indicadores de desempenho - áreas chave de gestão}

Um pequeno conjunto de indicadores de desempenho, associados às áreas chave de gestão, pode ser aplicado a maioria das empresas industriais ou de serviço, conforme descrito a seguir: (INDICADORES, 2000)

Eficiência:

- relação da quantidade de recursos utilizada para produzir os produtos ou os serviços.

Preço:

- relação entre o preço médio praticado pela empresa e o preço médio praticado pela concorrência;

- índice de rejeição de preços, associado à relação do número de negócios perdidos por preço e do número de negócios tentados.

\section{Qualidade:}

- índice de rejeição associado ao número de produtos devolvidos em relação ao número de produtos entregues;

- índice de retrabalho, associado ao volume de retrabalho para correções de produtos entregues em relação ao volume de trabalho efetivo da empresa;

- índice de satisfação do cliente associado a uma nota de avaliação obtida através de pesquisa de satisfação dos clientes sob vários aspectos dos produtos ou serviços, realizada periodicamente.

\section{Prazo de entrega:}

- relação entre o prazo de entrega oferecido ao cliente e o prazo de entrega desejado pelo cliente;

- relação entre o prazo de entrega da empresa e o prazo de entrega dos concorrentes.

Pontualidade:

- relação entre o número de entregas em atraso e o número de fornecimentos realizados.

Tempo de processo:

- relação entre o tempo total para produção ou execução e o prazo de entrega do produto ou serviço.

Flexibilidade de produção:

- índice de excesso de capacidade disponível (break-even point baixo); 
- número de componentes e processos reutilizáveis;

- porcentagem de componentes reutilizáveis em cada produto.

\section{Serviços ao cliente:}

- tempo de atendimento ao cliente, ocorrido entre a chamada do serviço solicitado pelo cliente e a resolução do problema;

- tempo médio entre falhas (MTBF) para verificar a eficiência da manutenção.

Inovação:

- velocidade de introdução de novos produtos, associada à data de concepção da necessidade (normalmente anterior à data de início de projeto) e à data de comercialização das primeiras unidades;

- número de novos produtos por ano.

Marketing e vendas:

- número de clientes ativos do ano corrente em relação ao número de clientes ativos do ano anterior;

- índice de desempenho de vendas, associado à quantidade realmente vendida em relação à projeção estabelecida para o período.

\section{Desempenho financeiro:}

- retorno sobre o capital investido;

- rentabilidade dos produtos e serviços.

Indicadores sociais:

- nível de satisfação dos funcionários obtido através de questionário de pontuação que avalia os aspectos do ambiente de trabalho (envolvimento, coesão, suporte dos supervisores, autonomia, orientação de tarefas, pressão no trabalho, clareza de tarefas e objetivos, controle, inovação, conforto físico).

\subsubsection{Indicadores de desempenho - processos da incubadora e das empresas incubadas}

A verificação das melhores práticas encontradas durante o levantamento de processos na estrutura da incubadora e nas empresas incubadas também gera um conjunto balizador de indicadores de desempenho, conforme apresentado a seguir:

- planejamento estratégico;

- acompanhamento junto aos clientes em pós-vendas;

- acompanhamento de propostas;

- fluxo de caixa (contas a pagar e receber);

- simulação empresarial com a formulação de cenários de negócio;

- desenvolvimento de produto (hardware e software);

- treinamento do corpo funcional;

- cadastro de clientes;

- definição de produtos;

- acompanhamento e análise de mercado;
- apoio de projetos de fomento empresarial;

- integração do corpo funcional (crenças e valores);

- formação da imagem da empresa.

\subsection{Elaboração da planilha de coleta e verificação dos indicadores}

A linha base de formação do conjunto inicial de indicadores de desempenho para a incubadora e suas empresas incubadas seguiu as características apresentadas. Complementar a linha base de indicadores tornou-se necessário para implantação de um formulário de registro, bem como um conjunto de recomendações para a rotina de coleta e verificação dos indicadores de desempenho.

Os indicadores de desempenho foram estabelecidos sob as perspectivas do Balanced Scorecard - financeira, clientes, processos internos e aprendizado/ crescimento, segundo um conjunto de características que definem uma empresa graduada no processo de incubação (objetivo fim da incubadora). Também foram considerados os fatores críticos de sucesso de empreendimentos levantados pelo SEBRAE-SC (2001), indicadores de desempenho em áreas chave e o conjunto de melhores práticas encontradas nos processos das empresas incubadas apresentados anteriormente.

Uma planilha de indicadores foi montada para coletar as medidas indicativas da situação da empresa em relação às perspectivas e às características estabelecidas (Tabela $3 \mathrm{e}$ Anexo A).

Um conjunto amplo de indicadores foi estabelecido, buscando um mapeamento amplo do desempenho da empresa. O modelo de indicadores é bastante flexível, permitindo o ajuste das características associadas às perspectivas do $B a$ lanced Scorecard, bem como a inclusão ou retirada de indicadores conforme as necessidades de aplicação nas empresas.

Uma recomendação adicional é a aplicação dos indicadores, considerando o tempo de incubação das empresas. A planilha de indicadores pode ser reduzida, buscando uma simplificação para aplicação em empresas no primeiro período de incubação e gradativamente ser complementada nos demais períodos.

\section{CONCLUSÃO}

Com o avanço da concorrência, uma das tendências no campo empresarial é a necessidade de os executivos adotarem uma postura estratégica. Para tanto, devem compreender o que se passa na empresa e em seu entorno (FISCHMANN; ZILBER, 2001). Modelos de gestão baseados em processos e indicadores já são aplicados em empresas com fins lucrativos há alguns anos. Esta abordagem, entre outros 
pontos, já se encontra na base de sistemas de informação de apoio à gestão empresarial. Este tipo de modelo de gestão passou, recentemente, a ser adotado por instituições governamentais ou pára-governamentais. Estudos, como o de Fischmann e Zilber (2001), demonstram a pertinência e viabilidade de um sistema de indicadores de desempenho como instrumento de gestão estratégica em organizações que têm ou buscam sucesso.

Cabe ressaltar também que o movimento de melhoria gerencial das incubadoras de empresa encontra-se em fase inicial. Este movimento deve ganhar força na medida em que os recursos para financiamento das mesmas se tornem ou mais escassos ou mais disputados (maior número de incubadoras). Atrelada a isto tem-se uma maior preocupação com eficiência/eficácia dos recursos aplicados pelas instituições financiadoras (CAULLIRAUX et al., 2001).

A proposta para a incubadora empresarial de base tecnológica foi desenvolvida conforme as modernas linhas de Sistemas e Tecnologia de Informação (REZENDE; ABREU, 2002) e de Monitoria, buscando com isso uma inovação na gestão das incubadoras e das empresas residentes, com o objetivo de atrair um maior número de recursos e assim

Tabela 3: Indicadores sob a perspectiva BSC.

\begin{tabular}{|c|c|c|}
\hline $\begin{array}{l}\text { Perspectivas } \\
\text { BSC }\end{array}$ & $\begin{array}{l}\text { Característica da } \\
\text { empresa graduada }\end{array}$ & Indicadores \\
\hline \multirow[t]{2}{*}{ Financeira } & Desempenho financeiro & $\begin{array}{l}\text { - Está associado basicamente ao retorno sobre o capital investido e a } \\
\text { rentabilidade dos produtos e serviços } \\
\text { - É verificado através de dados econômicos e financeiros da empresa } \\
\text { originados de balanços e balancetes contábeis, bem como dos } \\
\text { dados gerenciais (mensais ou anuais) } \\
\text { - Uma simples avaliação do capital da empresa pode ser } \\
\text { estabelecida para a fase inicial da empresa } \\
\text { - Estes indicadores são considerados básicos para a gestão } \\
\text { empresarial }\end{array}$ \\
\hline & $\begin{array}{l}\text { Desenvolvimento e implantação } \\
\text { do plano de negócio }\end{array}$ & $\begin{array}{l}\text { - Está associado especificamente ao atendimento do roteiro ou plano } \\
\text { de negócios estabelecido para a entrada no processo de incubação } \\
\text { - Verificado em pontos genéricos mensuráveis definidos no plano de } \\
\text { negócio } \\
\text { - Estes indicadores devem ser estabelecidos sobre as metas } \\
\text { estabelecidas pela empresa e seu respectivo cronograma }\end{array}$ \\
\hline \multirow[t]{3}{*}{ Clientes } & $\begin{array}{l}\text { Carteira de clientes que garanta } \\
\text { a sustentabilidade da empresa }\end{array}$ & $\begin{array}{l}\text { - A carteira de clientes é verificada através do desempenho em } \\
\text { propostas comerciais } \\
\text { - Uma avaliação dos clientes é estabelecida }\end{array}$ \\
\hline & $\begin{array}{l}\text { Visão de marketing implementada } \\
\text { (imagem da empresa constituída) }\end{array}$ & - Uma avaliação da projeção da empresa no mercado é estabelecida \\
\hline & Produtos e serviços definidos & $\begin{array}{l}\text { - A participação no mercado é dada pelos produtos e serviços } \\
\text { oferecidos e sua performance de negócio }\end{array}$ \\
\hline $\begin{array}{l}\text { Processos } \\
\text { internos }\end{array}$ & $\begin{array}{c}\text { Modelo de gestão constituído } \\
\text { e compartilhado nos membros } \\
\text { da empresa (áreas de } \\
\text { responsabilidade - funções e processos) }\end{array}$ & $\begin{array}{l}\text { - Estes indicadores são estabelecidos com base no modelo de } \\
\text { processos da empresa padrão levantado no MIDI-Tecnológico } \\
\text { - Os indicadores buscam verificar as atividades executadas na } \\
\text { empresa e o grau de formatação dos processos da empresa }\end{array}$ \\
\hline \multirow[t]{3}{*}{$\begin{array}{l}\text { Aprendizado e } \\
\text { crescimento }\end{array}$} & $\begin{array}{l}\text { Domínio tecnológico e competências } \\
\text { claramente definidas }\end{array}$ & $\begin{array}{l}\text { - Verificado através de atividades de treinamento realizadas na } \\
\text { empresa e na performance de pessoal }\end{array}$ \\
\hline & $\begin{array}{l}\text { Rede de } \\
\text { relacionamento } \\
\text { formada }\end{array}$ & $\begin{array}{l}\text { - A rede de relacionamento é estabelecida pelas parcerias } \\
\text { realizadas pela empresa, transferência tecnológica e pelos serviços } \\
\text { contratados por terceiros } \\
\text { - A quantidade de relacionamentos define o tamanho da rede } \\
\text { formada e mantida }\end{array}$ \\
\hline & $\begin{array}{c}\text { Habilidades empreendedoras } \\
\text { desenvolvidas (perfil do empreendedor) }\end{array}$ & - Uma avaliação das características empreendedoras é definida \\
\hline
\end{tabular}


aumentar as chances de sucesso das novas empresas. Fundamentalmente, manteve a preocupação em perpetuar seus benefícios junto à incubadora e suas empresas residentes.

Os resultados da proposta permitem dar maior consistência a todo o sistema de avaliação e acompanhamento das empresas incubadas, disponibilizando, permanentemente, à gestão da incubadora e suas empresas um Sistema de Informação Gerencial composto de banco de dados, software de gestão empresarial, equipamentos e redes integradas de comunicação.

\section{Artigo recebido em 08/07/2005 Aprovado para publicação em 02/01/2008}

\section{AGRADECIMENTOS}

A proposta apresentada foi submetida e aprovada para execução no Programa SEBRAE de Incubadoras de Empresas, Edital 03/2001, sob a modalidade de apoio às incubadoras de empresas que tenham até cinco anos de constituição (KIEFER, 2001; SEBRAE-SC, 2001). Foi desenvolvida na incubadora MIDI-Tecnológico - Microdistrito Industrial de Base Tecnológica (MIDI, 2001), que encampou uma ação estruturada sob um modelo de parceria triangular. Como resultado, para a execução do projeto foi estabelecida uma composição em parceria triangular com participação da Associação Catarinense de Empresas Tecnologia (ACATE), do Núcleo de Estudos em Inovação, Gestão e Tecnologia de Informação (IGTI) e da empresa VOID CAZ 0 - Consultoria e Sistemas Ltda. (FERREIRA et al., 2001).

São destacados agradecimentos ao Sr. Cleiton Arnor Zimmer, proprietário da empresa VOID CAZ O, ao Sr. Marcos Regueira, consultor do SEBRAE-SC e ao Sr. Baeter Nagib Elias, secretário executivo da ACATE, que contribuíram na elaboração e execução do projeto.

Ficam aqui também os mais expressivos agradecimentos ao SEBRAE pelo apoio do edital 03/2001, igualmente ao SEBRAE-SC pela atenção e dedicação de seus incansáveis consultores.

\section{REFERÊNCIAS}

ACATE. Associação Catarinense de Empresas Tecnologia. Disponível em: <www.acate.com. br>. Acesso em: 27 out. 2001.

ANPROTEC. Associação Nacional de Entidades Promotoras de Empreendimentos de Tecnologias Avançadas. Apresenta informações sobre entidades gestoras de tecnópolis/pólos, parques e incubadoras. Disponível em: $<w w w$.anprotec. org.br>. Acesso em: 23 set. 2001.

BASTO, M. L. S. L. Fatores inibidores e facilitadores ao desenvolvimento da criatividade em EBT: um estudo de caso. Dissertação (Mestrado em Engenharia da Produção) - Programa de Pós-graduação em Engenharia de Produção, Universidade Federal de Santa Catarina, Florianópolis, 2000.

CAULLIRAUX, H. M. et al. Incubadoras de empresas: modelo de gestão - estratégia, políticas operacionais, estrutura de indicadores de desempenho, modelo de avaliação e sistema integrado de gestão. Rio de Janeiro, GPI / EP \& COPPE / UFRJ, abril de 2001. Disponível em: $\langle$ www.redetec.org.br/reinc/documentos.html $>$. Acesso em: 27 out. 2001.
FERREIRA, M. P. Desenvolvimento de software alinhado aos objetivos estratégicos do negócio: proposta de uma metodologia. Dissertação (Mestrado em Engenharia de Produção) Programa de Pós-Graduação em Engenharia de Produção, Universidade Federal de Santa Catarina, Florianópolis, 2002.

FERREIRA, M. P. et al. Incubação de empresas: instituição da gestão baseada em indicadores de desempenho. In: ENCONTRO NACIONAL DE EMPREENDEDORISMO, 3., 2001. Anais. Florianópolis: ENE/UFSC, 2001.

FISCHMANN, A. A.; ZILBER, M. A. Utilização de indicadores de desempenho como instrumento de suporte à gestão estratégica. Disponível em: <www.informal.com.br/artigos/AE11.html>. Acesso em: 25 ago. 2001.

HERZOG, A. L. Tintim por tintim: gestão. Exame, 7 mar. 2001.

IGTI. Núcleo de Estudos em Inovação, Gestão e Tecnologia de Informação. Disponível em $<w w w . i g t i . u f s c . b r>$. Acesso em: 12 jul. 2001.
INDICADORES de desempenho para 12 áreas chave da sua empresa. FG\&A Software, 2000.

KAPLAN, R. S.; NORTON, D. P. A estratégia em ação: balanced scorecard. Rio de Janeiro: Campus, 1997.

KIEFER, R. SEBRAE libera R\$ 415 mil para sete incubadoras: beneficiados foram selecionados entre 19 projetos. Gazeta Mercantil, 25 out. 2001.

MCGEE, J. V.; PRUSAK, L. Gerenciamento estratégico da informação: aumente a competitividade e a eficiência de sua empresa utilizando a informação como uma ferramenta estratégica. 6. ed. Rio de Janeiro: Campus, 1994.

MEDEIROS, J. A. et al. Pólos, parques e incubadoras: a busca da modernização e competitividade. CNPq, IBICT, SENAI, 1992.

MIDI - Tecnológico. Apresentação do projeto MIDI e relação das empresas. Disponível em: $<$ http://www.miditecnologico.com.br $>$. Acesso em: 29 out. 2001. 
REZENDE, D. A.; ABREU, A. F. Tecnologia da informação aplicada a sistemas de informação empresariais: o papel estratégico da informação e dos sistemas de informação nas empresas. São Paulo: Atlas, 2002

RIGGS, H. E. Managing high-technology companies. New York: Van Nostrand Reinhold, 1983.

SEBRAE-SC. Pesquisa sobre mortalidade de empresa e seus fatores condicionantes. Coordenação de Cláudio Ferreira. Florianópolis, 1999.
SEBRAE-SC. Serviço de Apoio às Micro e Pequenas Empresas de Santa Catarina. Apresenta informações destinadas a atividades empreendedoras. Disponível em: $<w w w$. sebrae-sc.com.br>. Acesso em: 4 ago. 2001.

SEBRAE-SP. MPEs de Base Tecnológica: conceituação, formas de financiamento e análise de casos brasileiros, Serviço de Apoio às Micro e Pequenas empresas de São Paulo, julho de 2001. Disponível em: <http://www. sebraesp.com.br/sebrae/sebraenovo/pesquisa/ pdf_pesquisa/EMBATEC.pdf $>$ Acesso em: 21 nov. 2001.
SILVA NETO, A. B. Competitividade e desempenho competitivo no nível da firma: análise comparativa de conceitos e de indicadores. Dissertação (Mestrado em Economia) Programa de Pós-graduação em Economia, Universidade Federal de Santa Catarina, Florianópolis, 2000.

VOID CAZ 0 - Consultoria e Sistemas Ltda. Apresenta banco de informações. Disponível em: <www.voidcaz.com.br>. Acesso em: 27 out. 2001.

\section{SOBRE OS AUTORES}

\section{Mauro Pacheco Ferreira}

Universidade do Sul de Santa Catarina (UNISUL)

End.: Rua Prefeito Reinaldo Alves, 25 - Passa Vinte - Palhoça - SC - 88130-000

Tel.: (48) 9980-5293

E-mail: pacheco@unisul.br

\section{Aline França de Abreu}

Departamento de Engenharia de Produção e Sistemas

Universidade Federal de Santa Catarina (UFSC)

End.: Caixa Postal 476, Campus Universitário - Trindade - Florianópolis - SC - 88010-970

Fone: (48) 3721-7015

E-mail: aline@deps.ufsc.br

\section{Pedro Felipe de Abreu}

Departamento de Engenharia de Produção e Sistemas

Universidade Federal de Santa Catarina (UFSC)

End.: Caixa Postal 476, Campus Universitário - Trindade - Florianópolis - SC - 88010-970

Fone: (48) 3721-7015

E-mail: pedro@deps.ufsc.br

\section{Dorzeli Salete Trzeciak}

Departamento de Engenharia de Produção e Sistemas

Universidade Federal de Santa Catarina (UFSC)

End.: Caixa Postal 476, Campus Universitário - Trindade - Florianópolis - SC - 88010-970

Fone: (48) 3721-7015

E-mail: dorzeli@deps.ufsc.br

\section{Luiz Gonzaga Apolinário}

Incubadora MIDI-Tecnológico

End.: Rua Aldo Alves, 453, Saco dos Limões - Florianópolis - SC - 88045-600

Tel.: (48) 3333-8373

E-mail: Igapolinario@yahoo.com.br

\section{Alexandre d'Avila da Cunha}

ACATE - Associação Catarinense de Empresas de Tecnologia

End.: Rua Lauro Linhares, 589, 3o andar - Trindade - Florianópolis - SC - 88036-002

Tel.: (48) 2107-2700

E-mail: presidente@acate.com.br 


\section{ANEXO - PLANILHA DE COLETA DE DADOS}
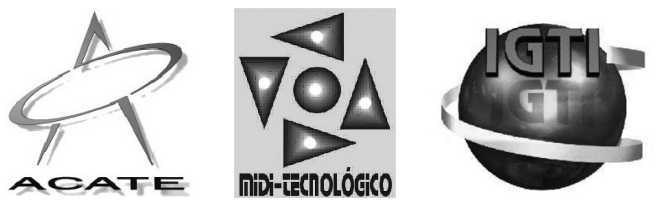

PROJETO DA INCUBADORA MIDI-TECNOLÓGICO

Programa SEBRAE de Incubadoras de Empresas

Edital 03/2001

Fortalecimento do Processo de Incubação de Empresas

Através da Instituição da Gestão Empresarial Baseada em Indicadores de Desempenho

e Suportada por um Sistema Básico de Qualidade

Planilha de Indicadores de Desempenho

versão 2.02
Legenda:

valor a ser entrado pelo usuário

valor calculado pela planilha

\section{Referência da coleta de dados}

Empresa:

Mês referência:

Data:

Responsável:

\section{DADOS DE REFERÊNCIA}

Número de colaboradores:

Quantidade de homem/hora disponível no mês:

Valor do h.h. de mercado (R\$):

\section{Perspectiva Financeira}

\section{Desempenho financeiro}

\section{DADOS DO BALANÇO PATRIMONIAL (ANUAL)}

\section{Ativo - Bens e direitos}

Circulante $(\mathrm{R} \$)$ :

Realizável a longo prazo (R\$):

Permanente (R\$):

Total Ativo

Detalhes do ativo circulante

Estoque (R\$):

\section{Passivo - Obrigações}

Circulante $(\mathrm{R} \$)$ :

Exigível a longo prazo (R\$):

Patrimônio líquido:

Total Passivo nome da empresa

mês/ano

$\mathrm{dd} / \mathrm{mm} / \mathrm{aa}$

nome do responsável
0

0

0,00

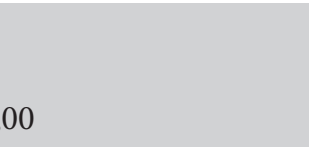

$0,00 \quad *$ prazo $<360$ dias: disponibilidades, contas a receber, estoque, outros

$0,00 \quad *$ prazo $>360$ dias

$0,00 *$ imobilizado, outros

0,00

\section{0,00}

$0,00 \quad *$ prazo $<360$ dias: contas a pagar, empréstimos, obrigações

$0,00 \quad *$ prazo $>360$ dias

$0,00 *$ capital social, lucro/prejuízo acumulados

0,00 
Detalhes do patrimônio líquido

Capital social:

0,00

0,00

Reservas:

Resultado do exercício (lucro/prejuízo):

\section{INDICADORES DO BALANÇO PATRIMONIAL}

Lucratividade $(\%)=$

* mede a eficiência da empresa

Rentabilidade $(\%)=$

* mede a eficácia da empresa

Prazo de retorno do investimento (meses) $=$

* tempo para retornar o investimento
\#\#\#\# * ativo circulante/resultado do exercício

\#\#\#\# $\quad *$ lucro / patrimônio líquido

\#\#\#\#\# $\quad *$ (capital social + reservas $) /$ lucro

Liquidez

* capacidade de pagar compromissos de curto prazo

Liquidez imediata $=$

Liquidez seca $=$

Endividamento (\%) =

* nível de endividamento da empresa

\section{DADOS GERENCIAIS (MENSAIS)}

Faturamento

Custos fixos

Custos Variáveis

Impostos

\section{Ativo - Bens e direitos}

Disponibilidades:

Contas a receber:

Permanente avaliado:

Total Ativo

\section{Passivo - Obrigações}

Dívidas:

Contas a pagar:

Impostos a pagar:

Patrimônio líquido $=$

Total Passivo

\section{INDICADORES GERENCIAIS (MENSAIS)}

Lucro $(\mathrm{R} \$)=$

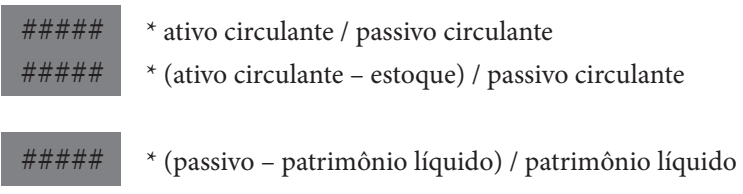

$\begin{array}{ll}0,00 & * \text { saldos disponíveis acumulados } \\ 0,00 & * \text { receitas do mês } \\ 0,00 & * \text { valor estimado da empresa } \\ 0,00 & \end{array}$

$0,00 *$ valor total de dívidas acumuladas da empresa

* despesas do mês= custo fixo + custos variáveis

0,00

0,00

0,00

* valor calculado da empresa

${ }^{*}$ contas a receber - contas a pagar - impostos 


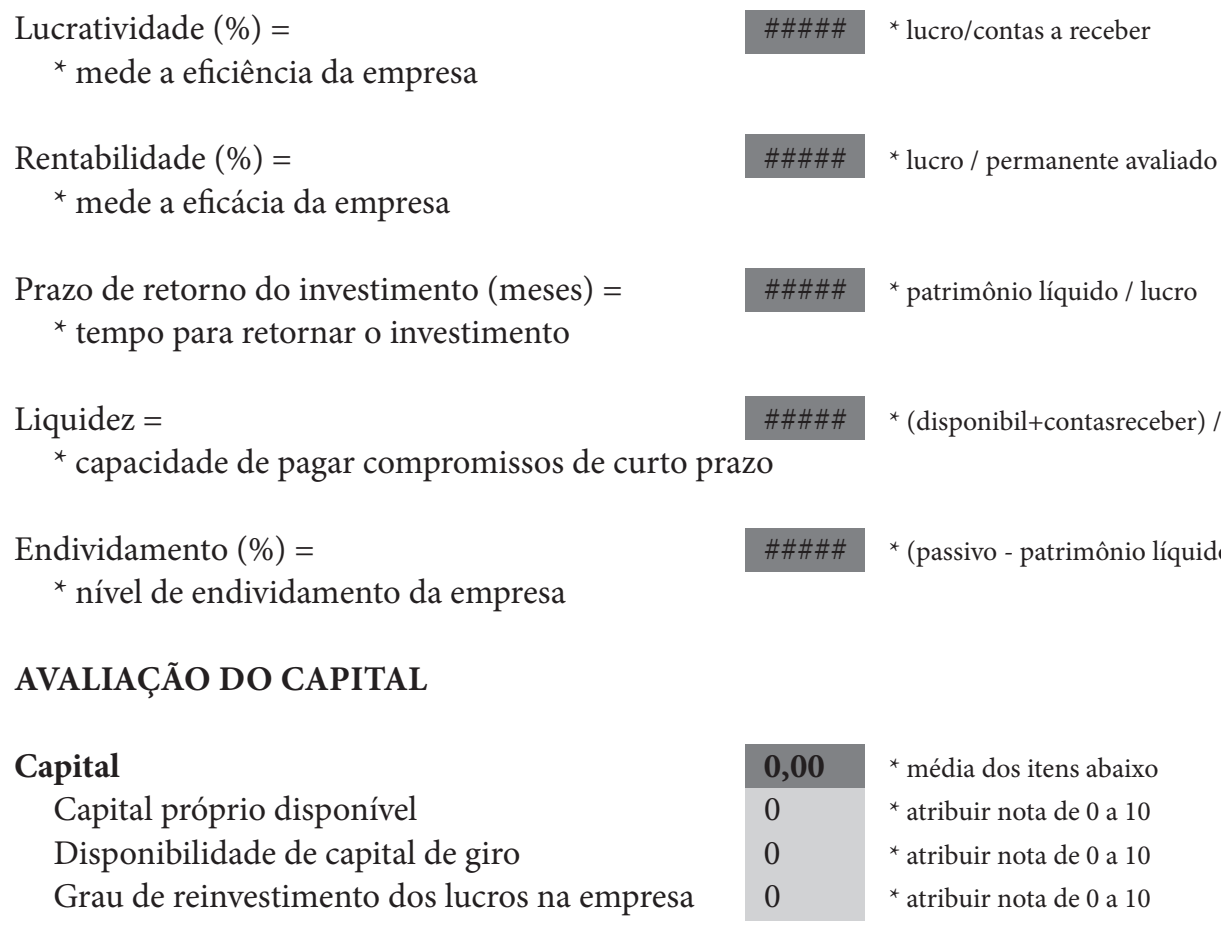

* nível de endividamento da empresa

\section{AVALIAÇÃO DO CAPITAL}

\section{Capital}

Capital próprio disponível

Disponibilidade de capital de giro

Grau de reinvestimento dos lucros na empresa

$\begin{array}{ll}\mathbf{0 , 0 0} & { }^{*} \text { média dos itens abaixo } \\ 0 & { }^{*} \text { atribuir nota de } 0 \text { a } 10 \\ 0 & { }^{*} \text { atribuir nota de } 0 \text { a } 10 \\ 0 & { }^{*} \text { atribuir nota de } 0 \text { a } 10\end{array}$

\section{Desenvolveu e implantou o plano de negócios}

\section{Metas e cronograma}

No. de metas estabelecidas

No. total de metas alcançadas

No. de metas alcançadas no prazo

Índice de desenvolvimento das metas

Performance cronológica

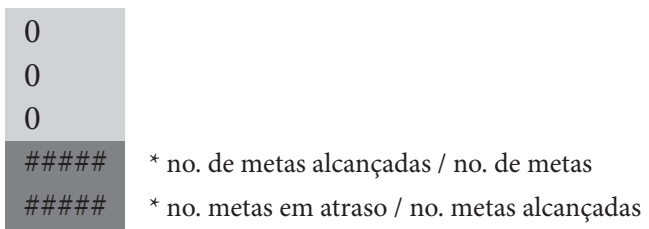

\section{Perspectiva dos clientes}

\section{Carteira de clientes que garanta a sustentabilidade da empresa}

\section{Propostas}

No. de propostas realizadas:

No. de propostas contratadas:

No. de propostas perdidas por preço:

Performance das propostas

Índice de rejeição por preço

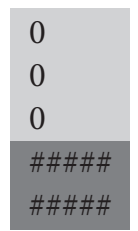

* no. de propostas contratadas / no. de propostas realizadas

* no. de propostas perdidas por preço / no. propostas perdidas

\section{Clientes}

No. de clientes ativos:

No. de clientes "maus pagadores"

Risco dos clientes

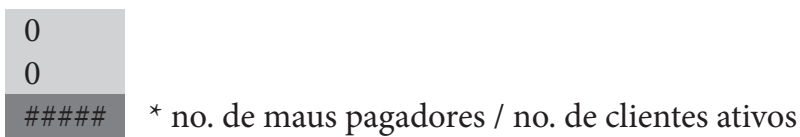




\section{Perfil do cliente}

Perfil socioeconômico da clientela

Qualidade dos clientes

$\begin{array}{ll}0,00 & * \text { média dos itens abaixo } \\ 0 & * \text { atribuir nota de } 0 \text { a } 10 \\ 0 & * \text { atribuir nota de } 0 \text { a } 10\end{array}$

\section{Visão de marketing implementada (imagem da empresa constituída)}

\section{Projeção no mercado}

Boa estratégia de vendas implementada

Nível de conhecimento do mercado onde atua

Nível de conhecimento do cliente

Aproveitamento das oportunidades de negócio

$\begin{array}{ll}0,00 & { }^{*} \text { média dos itens abaixo } \\ 0 & { }^{*} \text { atribuir nota de } 0 \text { a } 10 \\ 0 & { }^{*} \text { atribuir nota de } 0 \text { a } 10 \\ 0 & { }^{*} \text { atribuir nota de } 0 \text { a } 10 \\ 0 & { }^{*} \text { atribuir nota de } 0 \text { a } 10\end{array}$

Produtos e serviços definidos

No. de serviços oferecidos

No. de produtos oferecidos

Total de produtos e serviços

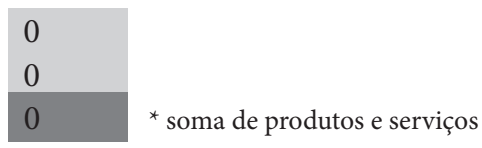

No. de produtos e serviços entregues:

No. de produtos devolvidos ou reclamados:

No. de fornecimentos atrasados:

Quantidade de h.h. trabalhado em manutenções

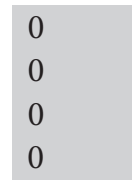

Índice de retrabalho $(\%)=$

Índice de rejeição por qualidade $(\%)=$

Pontualidade (\%)

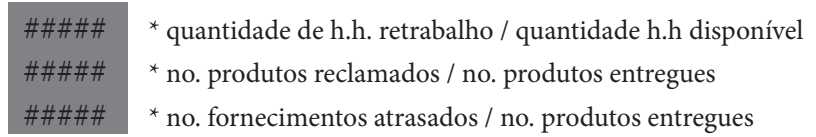

\section{Processos Internos}

\section{Modelo de gestão constituído e compartilhado nos membros da empresa}

\section{Funcionograma}

Diretoria

Administrativo

Financeiro

Comercial

Marketing

Desenvolvimento de produto

Produção

Execução técnica

Suporte

Total de funções realizadas

Índice de alinhamento funcional ao modelo padrão

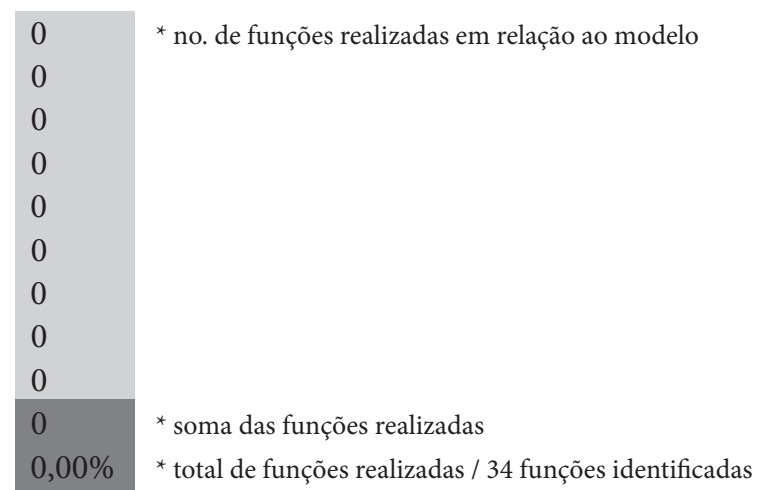

\section{Processos}

no. de processos identificados na empresa no. de processos formais

Grau de formalização de processos

0
0
$\# \# \# \#$


Serviços da empresa

Boa administração

Boa contabilidade

Grau de terceirização das atividades meio da empresa

Facilidade de acesso a novas tecnologias

Informações sobre legislações

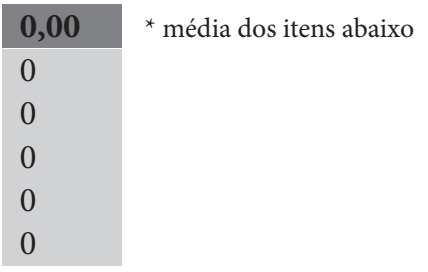

\section{Aprendizado e Crescimento}

\section{Domínio tecnológico e competências claramente definidas}

No. de colaboradores que realizaram treinamento:

No. h.h. em treinamento:

0

0

Treinamento

Relação h.h (\%) =

Relação colaboradores $(\%)=$

Eficiência $(\mathrm{R} \$ /$ colaborador $)=$

Eficiência $(\mathrm{R} \$ / \mathrm{h} . \mathrm{h})=$.

* quantidade de recursos para produzir os resultados

h.h referência $(\%)=$

* relação entre o h.h. da empresa e do mercado
\#\#\#\#\# $\quad{ }^{*}$ no. h.h. em treinamento / no. h.h disponível

\#\#\#\#\# $\quad *$ no. colaboradores em treinamento / no. colaboradores

\section{Rede de relacionamento formada}

No. de parcerias formais

No. de parcerias informais

\#\#\#\#\# * contas a receber / no. colaboradores

\#\#\#\#\# * contas a receber / quantidade de h.h. disponível

No. convênios de transferência tecnológica

No. de serviços de terceiros contratados

Total de relacionamentos

\#\#\#\# * eficiência / valor de h.h de mercado

\section{Habilidades empreendedoras desenvolvidas (perfil do empreendedor)}

\section{Perfil dos empresários}

Capacidade de liderança

Capacidade para assumir riscos

Nível de criatividade

Grau de persistência/perseverança

Experiência no negócio

Harmonia entre sócios

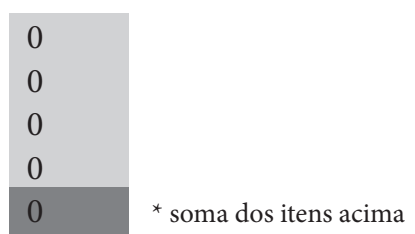

$\begin{array}{ll}0,00 & * \text { média dos itens abaixo } \\ 0 & * \text { atribuir nota de } 0 \text { a } 10 \\ 0 & * \text { atribuir nota de } 0 \text { a } 10 \\ 0 & * \text { atribuir nota de } 0 \text { a } 10 \\ 0 & * \text { atribuir nota de } 0 \text { a } 10 \\ 0 & * \text { atribuir nota de } 0 \text { a } 10 \\ 0 & \text { * atribuir nota de } 0 \text { a } 10\end{array}$

